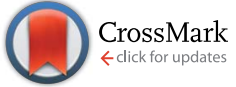

Cite this: RSC Adv., 2017, 7, 694

Received 27th October 2016 Accepted 1st December 2016

DOI: 10.1039/c6ra25921a

www.rsc.org/advances

\section{A simple process step for tuning the optical emission and ultraviolet photosensing properties of sol-gel ZnO film}

\begin{abstract}
Shuvaraj Ghosh and Durga Basak*
A simple process step involving controlled cooling action was successfully established for defect control in a sol-gel ZnO film. In this study, a sol-gel process was adapted to form two sets of ZnO films with two different pre-heat treatment temperatures (set $A$ and set B), but with the same post-heat treatment temperatures subjected to three different cooling rates $\left(0.12,0.25\right.$ and $\left.90{ }^{\circ} \mathrm{C} \mathrm{s}^{-1}\right)$ for each set in order to control the defect formation. The structural and surface morphological results showed that $\mathrm{ZnO}$ films, for both the sets, exhibited a wurtzite structure, whereas the crystallite orientations, FWHM of the (002) peak and the surface roughness, were found to vary with the cooling rate irrespective of the pre-heat treatment temperature. The films showed phenomenal changes in the photoluminescence $(\mathrm{PL})$ and ultraviolet photoconductivity (PC) results. Irrespective of the set type, the rapidly cooled $\left(90{ }^{\circ} \mathrm{C} \mathrm{s}^{-1}\right)$ films showed an improved ultraviolet-to-visible PL intensity ratio as compared to others as a result of reduced defect emission in the visible region. The dark and photo current measurement results indicated the existence of higher adsorbed $\mathrm{O}_{2}$ molecules-related trap states and an enhanced UV photoresponse in rapidly cooled films for both the sets, providing strong evidence in support of defect control. X-ray photoelectron spectroscopy results confirmed the presence of larger adsorbed $\mathrm{O}_{2}$ molecules at the strained oxygen vacancy sites in the rapidly cooled films. These results demonstrated that the post-heat treatment cooling rate could be a brilliant and easy pathway to control the defects for tuning the optical emission and ultraviolet photosensing properties of sol-gel ZnO films.
\end{abstract}

\section{Introduction}

ZnO, II-VI semiconductor material belonging to the wurtzite family, has a wide range of applications, from skin care, phosphors, and varistors to transparent electrodes in displays, piezoelectric devices and the biomedical field. ${ }^{1-5}$ This oxide material has received significant attention due to its application in optoelectronic devices, such as UV detectors, LEDs and LDs, for its direct and wide band gap of $3.37 \mathrm{eV}$ at room temperature. $^{6-10}$ Under above band gap photoexcitation, $\mathrm{ZnO}$ radiates light in the UV region at around $380 \mathrm{~nm}$. This photoluminescence in the UV region is due to recombination of excitons as $\mathrm{ZnO}$ has a very large exciton binding energy of about 60 $\mathrm{meV}$, making the excitons stable at room temperature. ${ }^{11-13}$ Therefore, $\mathrm{ZnO}$ is a very important material for UV light emission and laser diodes. In addition to the sharp and strong UV emission, a broad peak in the visible region is found in almost all $\mathrm{ZnO}$ grown irrespective of the growth technique. The nature and intensity of the visible emission has been the subject of immense research for decades since the origin of the visible emission is not conclusively clear yet. Oxygen vacancies $\left(\mathrm{V}_{\mathrm{O}}\right)$ and other intrinsic

Department of Solid State Physics, Indian Association for the Cultivation of Science, Jadavpur, Kolkata 700032, India. E-mail: sspdb@iacs.res.in defects have been thought to be responsible for these visible bands in addition to some impurities such as $\mathrm{Cu}^{2+}{ }^{24-17}$ However, these assignments have always become difficult due to complex origin of the defects as well as more than one of the defects being responsible for an emission. For example, it has been proposed that holes can be trapped at the surface and that the green emission is due to the recombination of excited electrons with these deeply trapped holes. ${ }^{18}$ However, it is well understood that both UV and visible emissions strongly depend on the surface states as the surface depletion width, controlled by the defect concentration, influences both emission intensities. Therefore, a controlled processing is necessary to adjust the surface states in order to maximise the UV and minimise the visible emission. Towards this effort, there have been numerous reports on enhanced UV emission and/or UV/VIS emission ratio using doping, ${ }^{19,20}$ surface modification, ${ }^{21}$ changing the surface/volume ratio, etc. However, doping and surface modification involve either an extra dopant source or a further coating step. A growth method itself that is capable of controlling the emission property of $\mathrm{ZnO}$ films is highly desirable.

ZnO thin films were prepared using various growth techniques, such as RF magnetron sputtering, ${ }^{22-24}$ chemical vapor deposition, ${ }^{25}$ pulsed laser deposition (PLD) ${ }^{26}$ spray pyrolysis, ${ }^{27}$ photo-atomic layer deposition, ${ }^{28}$ metal organic chemical vapor 
deposition (MOCVD) ${ }^{29}$ molecular beam epitaxy (MBE) ${ }^{30}$ and solgel technique. ${ }^{31}$ The sol-gel process has several advantages over others due to its simplicity, excellent compositional control, safety, low cost of the apparatus and raw materials, homogeneity on the molecular level due to the mixing of liquid precursors and relatively lower crystallization temperature. ZnO thin film deposition by the sol-gel method requires a heat treatment in air at higher temperatures in order to oxidise the precursors of the zinc compound solution. In general, the heat treatment involves two steps: drying at lower temperatures to evaporate the organic solvents (known as pre-heat treatment), and at higher temperatures for the formation of $\mathrm{ZnO}$ (known as post-heat treatment). The drying temperature is often chosen such that it is good for solvent evaporation, organic compounds removal as well as close to the $\mathrm{ZnO}$ crystallization temperature. Therefore, a temperature range from $120{ }^{\circ} \mathrm{C}$ to $350{ }^{\circ} \mathrm{C}$ was chosen for the pre-heat treatment process. ${ }^{32}$ The temperature for post-heat treatment was chosen in the range of $500-600{ }^{\circ} \mathrm{C}$. It is also well known that the properties of $\mathrm{ZnO}$ films, deposited by the sol-gel technique, are determined by various parameters, such as precursor type and concentration, aging time, substrate, annealing temperature, and thickness. ${ }^{33} \mathrm{Kim}$ et al. have applied two different cooling rates for preparing $\mathrm{ZnO}$ films, one slow and one fast after the pre-heat treatment at $300{ }^{\circ} \mathrm{C}$, followed by a post-heat treatment at $550{ }^{\circ} \mathrm{C}$. Along with a detailed morphological change, they have reported a blue shift and higher intense UV near band edge (NBE) peak for the film that was cooled rapidly. However, the post-heat treatment is very important as it is the step when the $\mathrm{ZnO}$ crystallites are formed. The cooling step after the post-heat treatment is thus very crucial and appears to be an important factor that largely controls the surface properties, which has been rarely reported. Therefore, in the present study, we demonstrate a simple, low temperature, and low-cost technique for controlling the photoluminescence (PL) and UV photoconductivity (PC) properties of $\mathrm{ZnO}$ thin films. It was shown that irrespective of the pre-heat treatment temperature, a rapidly cooled film always showed a higher UV/VIS emission ratio compared to slowly cooled or normally cooled films due to defect control; this has been supported by the results of (PC) studies. This study paves a way through comprehensive and comparative PL and PC studies of process controlled sol-gel $\mathrm{ZnO}$ films that can be exploited to tune the optical emission properties and photoassisted conductivity of other oxides too.

\section{Experimental}

ZnO thin films were deposited on glass substrates using a sol-gel spin coating method. The glass substrates were cleaned and degreased ultrasonically using chromic solution, de-ionized water, $\mathrm{HCl}$ and $\mathrm{KOH}$, followed by acetone and methanol for $10 \mathrm{~min}$ each. The sol concentration was $0.1 \mathrm{M}$, which was prepared by adding the required amount of zinc acetate-dihydrate $\left[\mathrm{Zn}\left(\mathrm{CH}_{3} \mathrm{COO}\right)_{2^{-}}\right.$ $\cdot 2 \mathrm{H}_{2} \mathrm{O}$ ] with dehydrated isopropyl alcohol. Diethanolamine (DEA) was added to the solution as a sol stabilizer, followed by a thorough mixing with a magnetic stirrer at a speed of $400 \mathrm{rmp}$ at room temperature (RT) for two hours and was kept for 48 hours for aging. Two sets of films were prepared wherein the pre-heat treatment after coating was varied while keeping the post-heat treatment and thereafter the cooling steps exactly similar.

\section{For set A films}

The substrates were spin coated with the sol at $2500 \mathrm{rpm}$ and after each coating process, the substrates were dried at $120{ }^{\circ} \mathrm{C}$ for 10 minutes and then crystallized at $500^{\circ} \mathrm{C}$ for $30 \mathrm{~min}$ in air. The coating process was repeated 20 times. The final post-heat treatment was carried out at $500{ }^{\circ} \mathrm{C}$ for $1 \mathrm{~h}$ in air.

\section{For set B films}

The substrates were spin coated with the sol at $2500 \mathrm{rpm}$ and after each coating process, the substrates were dried at $120^{\circ} \mathrm{C}$ for 10 minutes and then crystallized at $350{ }^{\circ} \mathrm{C}$ for $20 \mathrm{~min}$ in air. The coating process was repeated 20 times. Similar to set A, the final post-heat treatment was carried out at $500{ }^{\circ} \mathrm{C}$ for $1 \mathrm{~h}$ in air.

Cooling processes after the final post-heat treatment for both set $\mathrm{A}$ and set $\mathrm{B}$ films were varied as described below:

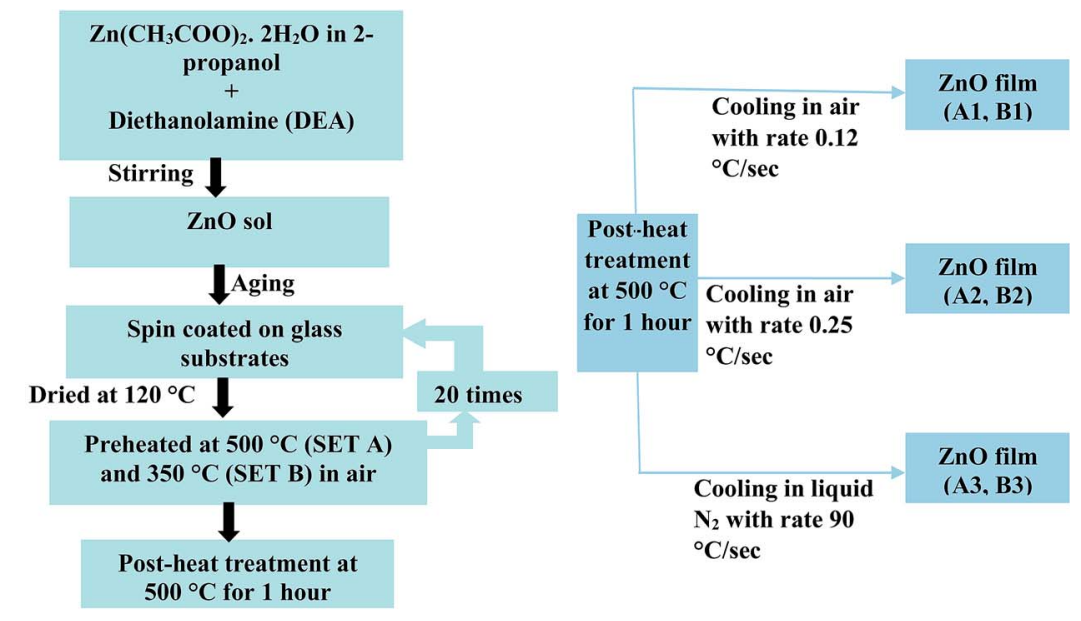

(A)

(B)

Scheme 1 Flow chart for preparation of $\mathrm{ZnO}$ films up to post-heat treatment (A) and different cooling steps after post-heat treatment (B). 
(1) Slow cooling (sample A1 and B1): the ZnO films were taken out from the furnace very slowly and cooled to RT. The average cooling rate was $0.12{ }^{\circ} \mathrm{C} \mathrm{s}^{-1}$.

(2) Normal cooling (sample $\mathrm{A} 2$ and B2): the $\mathrm{ZnO}$ films were taken out from furnace after annealing and kept at RT for cooling. The average cooling rate was $0.25{ }^{\circ} \mathrm{C} \mathrm{s}^{-1}$.

(3) Fast cooling (sample A3 and B3): the $\mathrm{ZnO}$ films were taken out from furnace and dropped very quickly into a container filled with liquid $\mathrm{N}_{2}$. The average cooling rate was $90{ }^{\circ} \mathrm{C} \mathrm{s}^{-1}$.

The purpose of varying the pre-heat treatment temperature while keeping the post-heat treatment temperature and thereafter the cooling steps exactly similar was to verify if the cooling rate affects the properties of $\mathrm{ZnO}$ films even when a different procedure is adopted for the film preparation. The summary of the entire growth technique for both the sets is shown in the following flow chart (Scheme 1).

The crystalline phase of the ZnO film was determined by an X-ray diffractometer (XRD) (model: X'pert pro, PANalytical) with
$\mathrm{CuK}_{\alpha}$ radiation $(1.5418 \AA)$. The surface texture and roughness were measured via field emission scanning electron microscopy (FESEM; model no. JEOL JSM-6700) and atomic force microscopy (AFM; VEECO model: diCP-II). For the measurement of PL property of the films at RT, an He-Cd laser (Kimmon Koha Co. Ltd.; model: KR1801C) with optical excitation line at $325 \mathrm{~nm}$ and a high-resolution spectrometer (Horiba Jobin Yvon, model: iHR 320) together with a photomultiplier tube were used. X-ray photoelectron spectroscopy (XPS, Omicron, serial no: 0571) results were studied to know the chemical states of the elements and contribution of surface adsorbed - $\mathrm{OH}$ group and $\mathrm{O}_{2}$ in the films. For dark and photocurrent measurements, two Al electrodes ( $1 \mathrm{~mm}$ diameter) of thickness about 40-60 $\mathrm{nm}$ separated by a $3 \mathrm{~mm}$ distance were evaporated onto $\mathrm{ZnO}$ films by a thermal evaporator (model: 12A4D, HHV). The direct currents between the two contacts were measured using a Keithley sourcemeter (model: 2400) and GPIB data transfer card. For photoresponse measurements, the photocurrents were
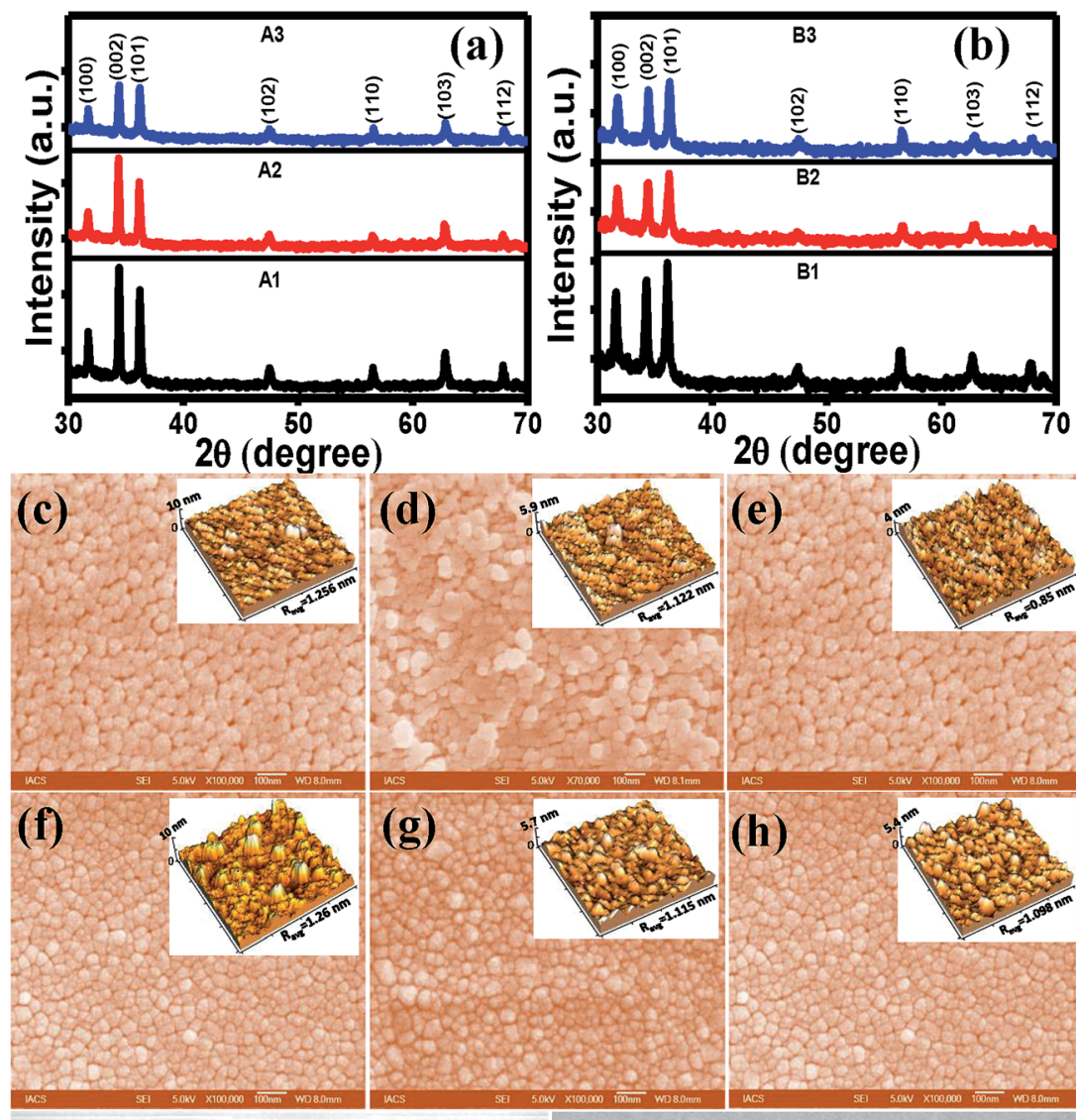

(e)

(i)
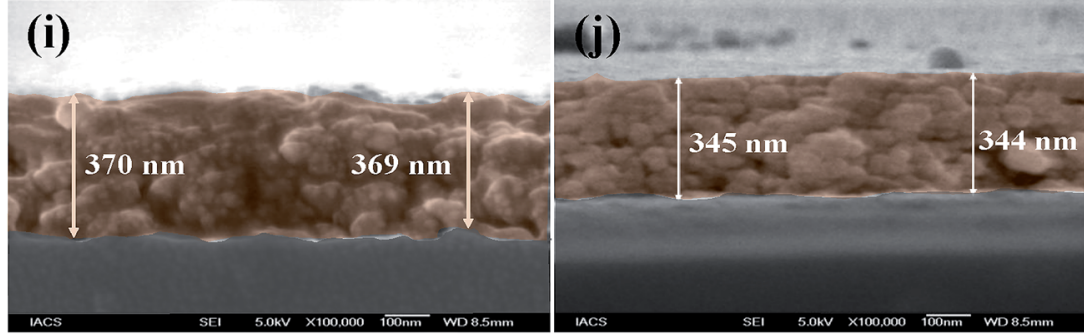

Fig. 1 XRD patterns of (a) set A and (b) set B films. The FESEM images of (c) A1 (d) A2 (e) A3 (f) B1 (g) B2 and (h) B3 films. The AFM images of the corresponding films are shown in the insets. The cross-section FESEM images of (i) $A 1$ and (j) $A 3$ showing the thicknesses of the films. 
measured by illuminating the film with a light wavelength $325 \mathrm{~nm}$ from a He-Cd laser source at a $10 \mathrm{~V}$ bias voltage. The films were kept in the dark for several hours to achieve the equilibrium before the dark current measurements. The photocurrent transients were measured under chopped illumination (420 s on and $600 \mathrm{~s}$ off) of UV light (325 nm, 35-40 mW), and the current value at $10 \mathrm{~V}$ applied bias at RT was measured simultaneously.

\section{Results and discussion}

The XRD patterns for all the films as presented in Fig. 1(a) and (b) showed multiple peaks due to (100), (002), (101), (102), (110), (103) and (112) planes of reflections for a single phase wurtzite structure of $\mathrm{ZnO}$ indicating random orientations of the crystallites. Considering the three major peaks, it is seen that orientations of the crystallites along (002) was quite higher than that along (100) and (101) planes for both set A and B films. FWHM value of the (002) peak was maximum for the B3 film, whereas it was minimum for the A3 film. A variety of factors can contribute to the width of an X-ray diffraction peak in addition to instrumental effects and crystallite size; the most important of these are usually inhomogeneous strain, crystal lattice imperfections such as dislocations, stacking faults, twinning, grain boundaries, sub-boundaries, chemical heterogeneities, and crystallite smallness. ${ }^{34}$ Therefore, a higher FWHM value of the B3 sample indicated poorer crystallinity as a result of rapid cooling. The $\mathrm{ZnO}$ formation procedures for set $\mathrm{A}$ and set $\mathrm{B}$ were different since the sols were subjected to different heat treatment. The XRD results of set B films indicated that heat treatment was the determining factor for the structural qualities. As the film cools, the film and the substrate contract in different amounts, displaying different thermal expansion coefficients, and thus a thermal strain is created in the film. ${ }^{35}$ The strain along the $c$ axis, $\varepsilon$ is given by the following equation: ${ }^{36}$

$$
\varepsilon=\left(C-C_{0}\right) / C_{0} \times 100 \%
$$

where $c$ is the lattice parameter of the strained $\mathrm{ZnO}$ films, which is calculated from X-ray diffraction data, and $C_{0}$ is the unstrained lattice parameter of $\mathrm{ZnO}^{37}$ The strain can be positive or negative indicating tensile or compressive strain, respectively. The values of strain computed using the abovementioned equation are tabulated in Table 1, which indicate a compressive strain for all the films. The maximum compressive strain values of -0.225 and -0.242 were noticed for A1 and B1, respectively, while the minimum values of -0.163 and -0.134 were noticed for A3 and B3 respectively. The minimum strain values in the rapidly cooled films indicated that stress relaxation time was reduced when the cooling rate was the highest, resulting in minimum strain in the films. ${ }^{38}$ The root mean square (RMS) roughness value as deduced from the AFM images revealed that the A3 and B3 films were smoother compared to other films in the respective series (Table 1). This was in accordance with the studies reported by M. S. Kim et al. ${ }^{39}$ The FESEM images (Fig. 1(c)-(h)) show a smooth morphology for all the films with not much variation in the grain size with the cooloing rate.
Table 1 FWHM, strain and average roughness values for set $A$ and set B films

\begin{tabular}{llll}
\hline Sample type & FWHM $(002)$ & Strain $\varepsilon(\%)$ & $\begin{array}{l}\text { Average roughness } \\
(\mathrm{nm})\end{array}$ \\
\hline A1 & 0.250 & -0.225 & 1.256 \\
$\mathrm{~A} 2$ & 0.242 & -0.184 & 1.122 \\
$\mathrm{~A} 3$ & 0.241 & -0.163 & 0.85 \\
B1 & 0.226 & -0.242 & 1.26 \\
B2 & 0.249 & -0.158 & 1.115 \\
B3 & 0.262 & -0.134 & 1.098
\end{tabular}

However, the A series films show slightly bigger grain size than those of the B series films.Thicknesses of the films for set A have been estimated from the cross section FESEM images to be $370 \mathrm{~nm}, 348 \mathrm{~nm}$ and $345 \mathrm{~nm}$ for A1, A2 and A3, respectively, whereas the thicknesses of the films for set $\mathrm{B}$ were found to be $447 \mathrm{~nm}, 414 \mathrm{~nm}$ and $396 \mathrm{~nm}$ for B1, B2 and B3, respectively. The representative cross-section images in Fig. 1(i) and (j) for A1 and A3 showed that there was a very small change in the thickness of the film that was rapidly cooled compared to the slowly cooled film.

The optical band gaps of the films are calculated from the transmission graph of the films using the fundamental absorption equation: ${ }^{40}$

$$
(\alpha h \nu)^{1 / n}=A\left(h \nu-E_{\mathrm{g}}\right)
$$

where $\alpha$ is the absorption coefficient, $h \nu$ is the incident photon energy, $E_{\mathrm{g}}$ is the band gap of $\mathrm{ZnO}$ and $A$ is a constant. The value of exponent term $n$ depends on the nature of the transition. The insets in the Fig. 2(a) and (b) show representative $(\alpha h \nu)^{2}$ versus $h \nu$ plots (Tauc plot) of sample A1 and B1 and the estimated values of band gap. A slight decrease in the band gap values was probably due to a decrease in the compressive strain similar to the studies reported earlier. ${ }^{\mathbf{1 1}}$

The PL spectra of all the films in Fig. 3(a) and (b) show that there is a sharp and intense UV peak at around $379 \mathrm{~nm}$, which is attributed to the band-edge excitonic emission and a broad peak at around $500 \mathrm{~nm}$ attributed to sub-band gap defects. Regardless of the exact origin of the visible emissions, the large visible $\mathrm{PL}$ intensity for the films A1 and A2 indicates that the films are rich in defects. In contrast to set A, the set B films also showed a more intense UV peak than the visible broad peak. The change in the PL properties was probably due to the difference in the heat treatment, as previously mentioned. However, it was noticed that for both the sets, as the cooling rate was controlled, the magnitude of the UV peak of the films remained almost unchanged, whereas the relative magnitude of the visible peak changed widely under the same experimental set-up and condition for the PL measurements. Similar change in the PL properties was observed for $\mathrm{TiO}_{2}$ films. ${ }^{42}$ The line shape of the visible peak for set B films is evidenced as the superposition of two peaks at around $500 \mathrm{~nm}$ (green luminescence, GL) and one at around $600 \mathrm{~nm}$ (orange-red luminescence, ORL). Therefore, we have fitted the broad peak into two peaks (GL and ORL), and in order to 

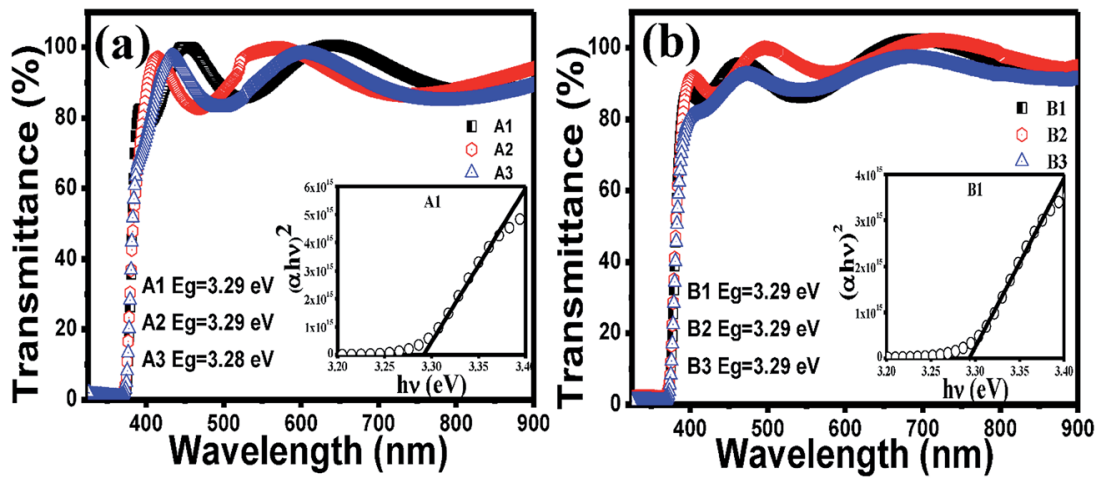

Fig. 2 Transmittance spectra of (a) set A and (b) set B films. The corresponding insets show the Tauc plots of a representative film and the values of band gaps estimated from the Tauc plots.

compare their intensities with the UV peak intensity, both $I_{\mathrm{UV}} /$ $I_{\mathrm{VIS}(\mathrm{GL})}$ and $I_{\mathrm{UV} /} / I_{\mathrm{VIS}(\mathrm{ORL})}$ values for set B films were evaluated. The values of $I_{\mathrm{UV}} / I_{\mathrm{VIS}}$ (Fig. 3(c) and (d)) were varied widely for the films processed under different cooling conditions. For $\mathrm{N}_{2}$ cooled films for both sets, the value of $I_{\mathrm{UV}} / I_{\mathrm{VIS}}$ is the maximum as compared to the other two films in the respective series (Fig. 3(c) and (d)). However, a 4-fold increase in the $I_{\mathrm{UV}} / I_{\mathrm{VIS}}$ value in $\mathrm{A} 3$ as compared to A1 could not be accounted for by the small change in the thickness of the film alone (Fig. 1(i) and (j)). The weaker defect emission intensity implies that the concentration of defects contributing to the radiative recombination for the green emission was very low. Due to rapid cooling, probability of adsorbed $\mathrm{OH}$ on the surface of the film was much less (since $-\mathrm{OH}$ is generally absorbed at $\sim 150{ }^{\circ} \mathrm{C}$ ) than the two other films. ${ }^{43}$
Therefore, from the experimental evidence, it may be mentioned that this surface adsorbed species indirectly control the green emission. To know the exact mechanism, the possible origins of the GL need to be analyzed further.

Several studies have been published regarding the origin of this band, using different experimental setups and different samples grown using various techniques. There may be multiple origins of this luminescence because different transitions can lead to quite similar luminescence emission wavelengths, thereby generating a great controversy about the GL in $\mathrm{ZnO}$. There are several hypotheses citing widely varied origins of $\mathrm{GL}$, such as, zinc vacancies $\left(\mathrm{V}_{\mathrm{Zn}}\right)$, oxygen vacancies $\left(\mathrm{V}_{\mathrm{O}}\right)$, interstitial zinc ions $\left(\mathrm{Zn}_{\mathrm{i}}\right)$, oxygen antisites $\mathrm{ZnO}$, transitions from $\mathrm{Zn}_{\mathrm{i}}$ to $\mathrm{V}_{\mathrm{Zn}}$, and impurity of $\mathrm{Cu}^{2+}$ ions..$^{14-17,23,44-48}$ Recently, it was
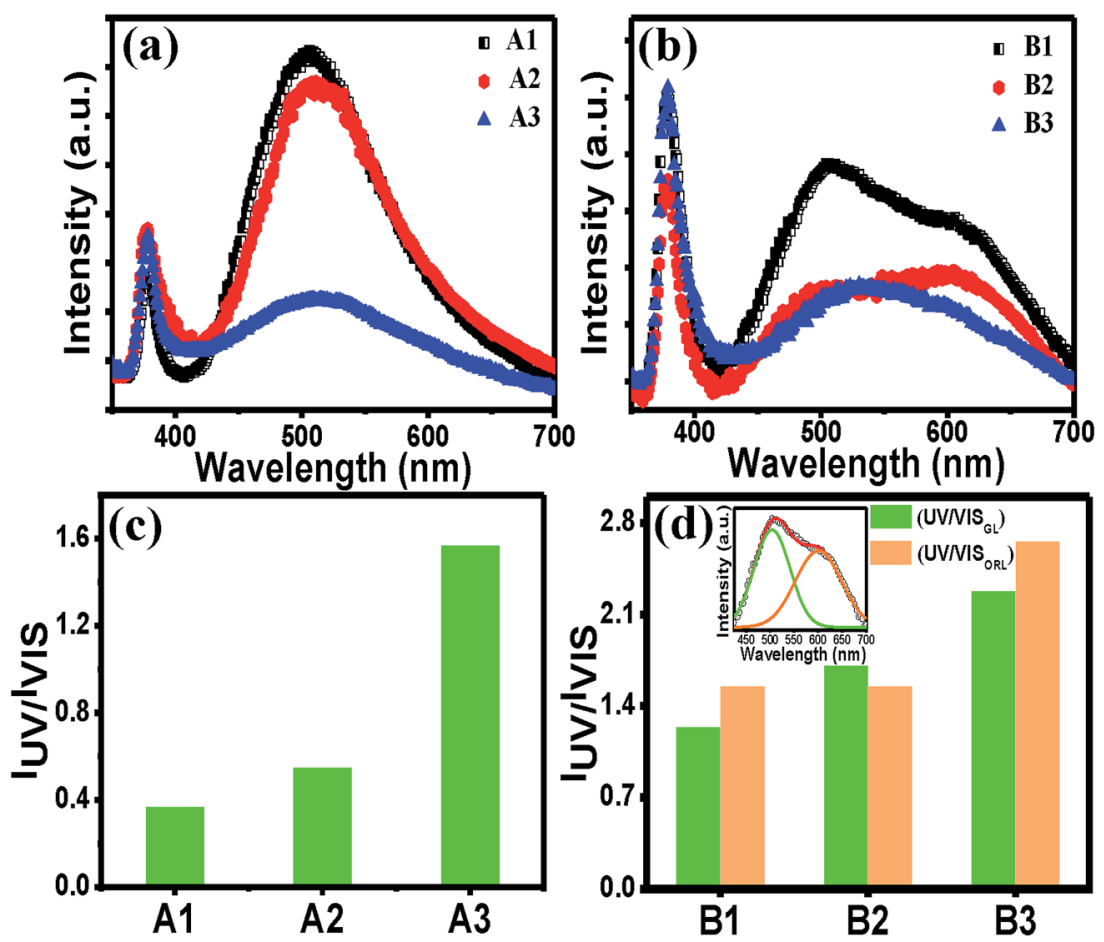

Fig. 3 Photoluminescence spectra of (a) set A and (b) set B films. UV/VIS intensity ratios of (c) set A and (d) set B films. The inset in (d) shows a representative theoretical Gaussian peak fittings of the visible peak. 
recognized that $\mathrm{V}_{\mathrm{Zn}}$ is a widely accepted defect to contribute to this green wavelength. ${ }^{43} \mathrm{~V}_{\mathrm{Zn}}$ are situated $0.9 \mathrm{eV}$ above the valence band minima, and hence a transition from the conduction band (or from a shallow donor) would yield a luminescence around $2.4 \mathrm{eV}$, which corresponds to the GL observed in $\mathrm{ZnO}$ samples grown using several techniques. It is likely that the surface adsorbed species generally heal the defects like $\mathrm{V}_{\mathrm{O}}$ or $\mathrm{V}_{\mathrm{Zn}} \cdot{ }^{49}$ Since surface adsorbed -OH species in rapidly cooled films is expected to be quite low, healing of the $\mathrm{V}_{\mathrm{Zn}}$ defects is also less probable, which means that these defects would satisfy their paring with other native defects forming complex defects such as $\mathrm{V}_{\mathrm{Zn}}-\mathrm{Zn}_{\mathrm{i}}$ Frenkel pair. ${ }^{50} \mathrm{~V}_{\mathrm{Zn}}$ is likely to form stable complexes with shallow donors in $\mathrm{ZnO} .{ }^{51}$ However, the defect complex of $\mathrm{V}_{\mathrm{Zn}}$ together with the shallow donor $\mathrm{Zn}_{\mathrm{i}}$ $\left(\mathrm{V}_{\mathrm{Zn}}+\mathrm{Zn}_{\mathrm{i}}\right)$ is a possible candidate for the orange luminescence (OL). ${ }^{52}$ GL was reduced in our study implying the probability of the defect complex to act as a radiative recombination centre for YL, and GL is supposedly less probable due to lesser compressive strain developed in the films. This has further implications that either of the individual defects plays a key role in GL. Previously it has been reported that heat treatment temperature and ambient temperature both control the $\mathrm{ZnO}$ film properties. ${ }^{53}$ In addition, irrespective of the heat treatments to form ZnO, a simple process, such as a cooling step applied after the post-heat treatment, is very much steering to tune its luminescence properties. A similar type of treatment was used by M. S. Kim et al. and they got a higher UV/VIS emission ratio for fast cooling. Compared with our results, their fast cooled sample showed much less visible emission, which indicates that their sample was completely healed by this treatment.

Further analyses of the UV peak in Fig. 4(a) and (b) showed that the UV peak for the both sets A and B were asymmetric on the higher wavelength side which was perfectly fitted with two Gaussian peaks, as shown in the respective insets in the figures. The higher energy peak corresponds to the exciton recombination $\left(1^{\text {st }} \mathrm{UV}\right)$, whereas the lower energy peak at around $388 \mathrm{~nm}$ is known to arise due to the recombination from the $\mathrm{Zn}_{\mathrm{i}}$ donor to the valence band. ${ }^{54}$ While the FWHM of the first UV peak remains almost unchanged irrespective of the cooling rate, the values for the second UV peak show a general increasing trend as the cooling rate is increased (Fig. 4(c) and 4(d)), indicating more spread of the energy level of the $\mathrm{Zn}_{\mathrm{i}}$ defects below the conduction band. This experimental result indicates that $\mathrm{Zn}_{\mathrm{i}}$ might have an attractive interaction with $\mathrm{V}_{\mathrm{Zn}}$ in the complex defects, as mentioned earlier.

The linear increase in the current with the bias voltage in the $I-V$ curves of the films for both sets (Fig. 5(a) and (b)) indicate an ohmic nature of the contacts with $\mathrm{ZnO}$ film. It was found that the dark currents for A3 and B3 were lower by two orders of magnitude than the other two in the series, whereas the value of the photocurrent did not differ much. It is known that $\mathrm{V}_{\mathrm{Zn}}$ does not contribute to p-type conductivity in $\mathrm{ZnO}$, but rather acts as a deep compensating center. ${ }^{55,56}$ If it had been the compensating centres, the magnitude of the photocurrent should not have been similar. Therefore, the presence of only $\mathrm{V}_{\mathrm{Zn}}$ is ruled out. The dark current largely depends on the surface adsorbed $\mathrm{O}_{2}$ molecules. ${ }^{57}$ Therefore, from the results it can be inferred
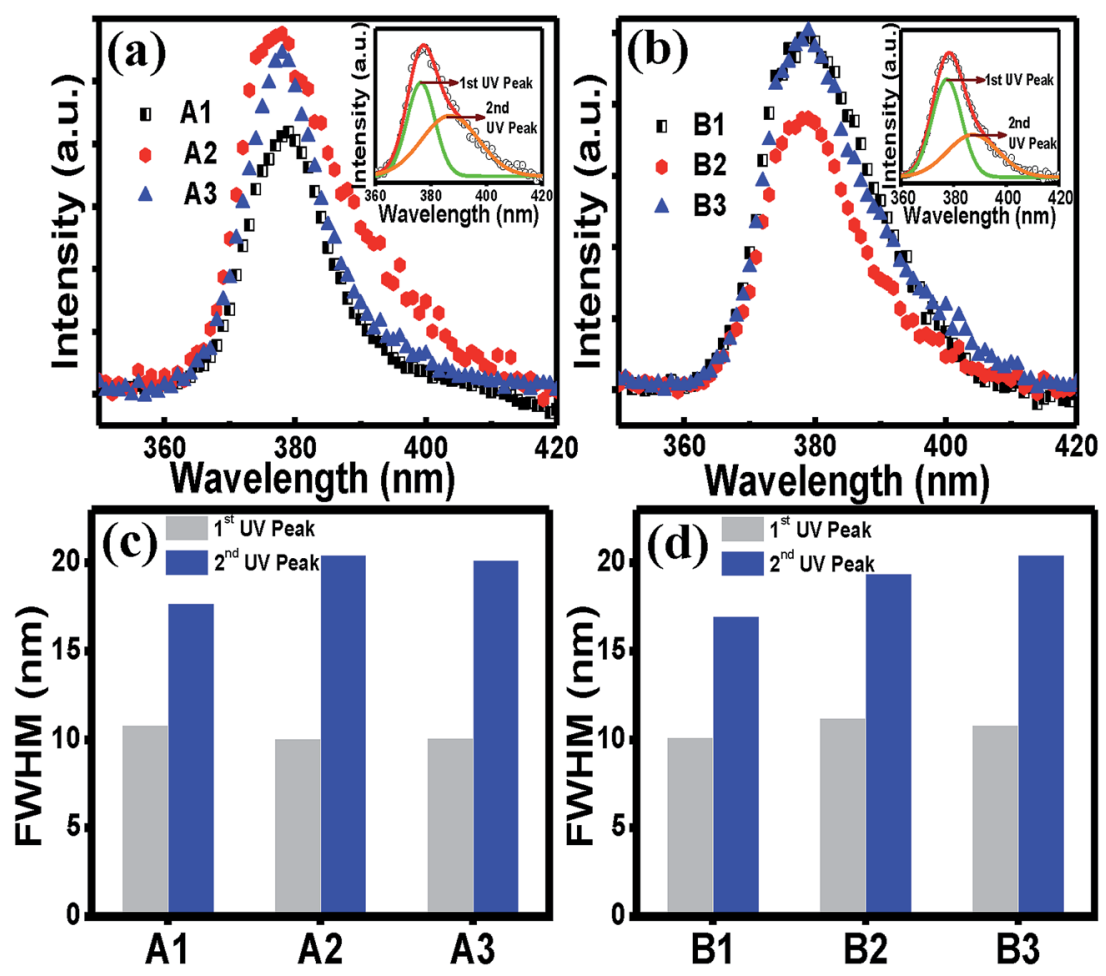

Fig. 4 Enlarged UV photoluminescence peak for (a) set A and (b) set B films. The corresponding inset shows a representative theoretical Gaussian peak fittings of the UV peak. The values of FWHM of the first and second UV fitted peaks for (c) set A and (d) set B films. 

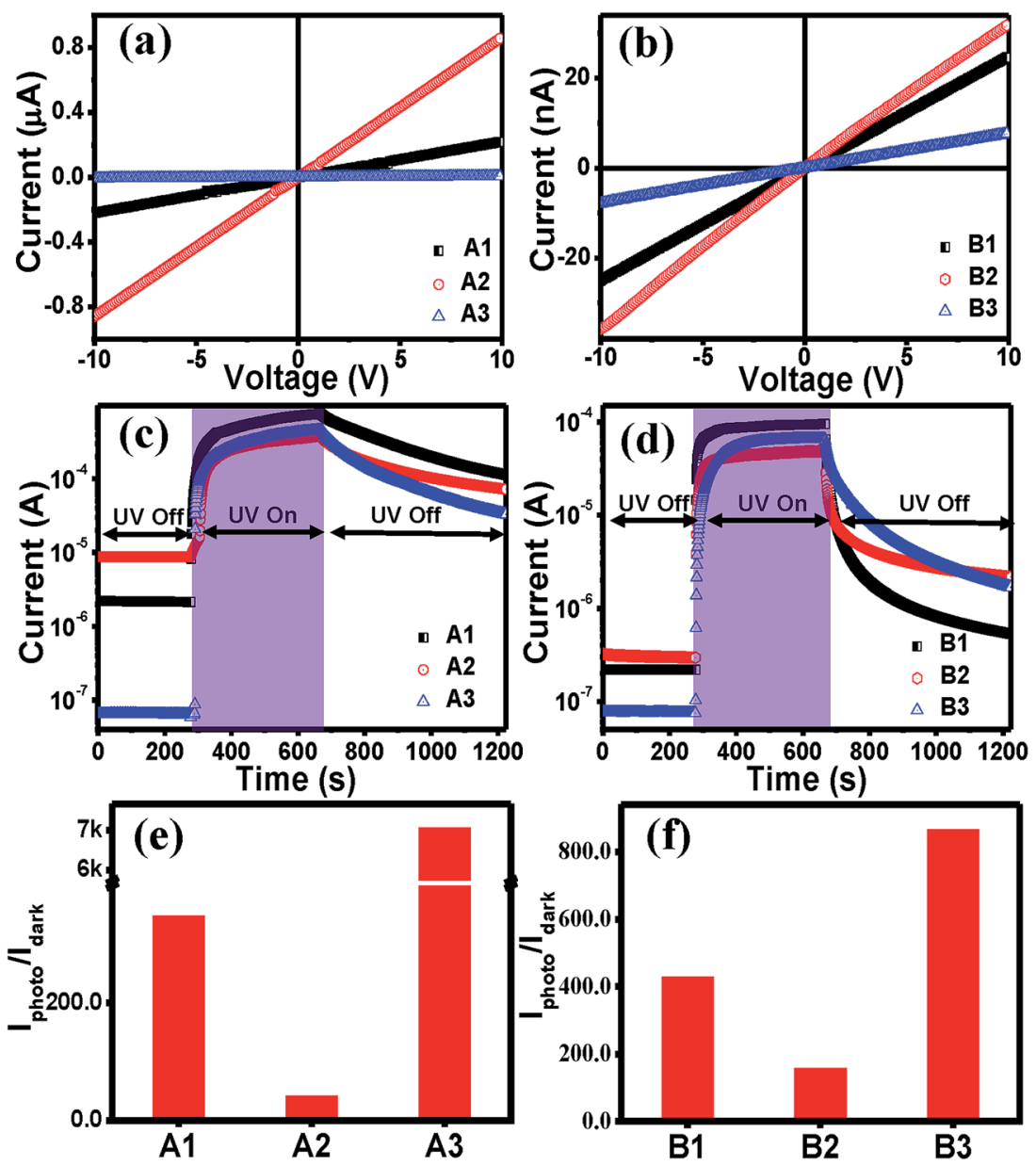

Fig. 5 Dark I-V curves of (a) set A and (b) set B films. Photocurrent transients for (c) set A and (d) set B films. The photo-to-dark current ratios of (e) set $A$ and (f) set $B$ films.

that $\mathrm{A} 3$ and $\mathrm{B} 3$, i.e. rapidly cooled films, might have a higher number of adsorbed $\mathrm{O}_{2}$ molecules, which may be attributed to the change in the strain values. The effect of strain on the adsorption of chemisorbed particles on surfaces offers a means of manipulating adsorption properties quite significantly. In an experimental study by Gsell et al.,$^{58}$ the preferential occupation of local areas with expanded lattices, as well as the depletion of compressed lattice areas, was demonstrated for $\mathrm{O}_{2}$ molecules adsorbed on $\mathrm{Ru}$ (0001). The photocurrent transient curves in Fig. 5(c) and (d) show that as soon as UV light (325 nm and power $35-40 \mathrm{~mW}$ ) was shined, the current increased very fast and when the light was turned 'Off', the current dropped. The recovery process in thin films is always slower than the response, as shown in earlier reports. ${ }^{59,60}$ This is due to the carrier trapping at the defects sites. The photo-to-dark current value i.e. the $\mathrm{UV}$ photoresponsivity value was much higher in both the A3 and B3 films, making them good UV photosensors. Such a high photo-to-dark current ratio has not been reported earlier for sol-gel ZnO films. ${ }^{61}$ For both sets of films, the current did not attain the dark value; this is consistent with the persistent photoconductivity (PP) phenomenon that is similar to previous reports. ${ }^{32}$
Having known that $-\mathrm{OH}$ could not get absorbed and the presence of more adsorbed $\mathrm{O}_{2}$ on the surface of the $\mathrm{ZnO}$ films of rapidly cooled films, the XPS tool was used to investigate the $\mathrm{O}$ content of the films. The XPS full scan for the films of set A and B show signals for only $\mathrm{Zn}, \mathrm{O}$ and $\mathrm{C}$ elements (Fig. 6), indicating no other impurities in the samples. The $\mathrm{O} 1 \mathrm{~s}$ core level peak was deconvoluted well into three peaks for $\mathrm{A} 2$ and into two peaks for A3. The peak centered at $530.4 \pm 0.3 \mathrm{eV}$ is associated with the $\mathrm{O}^{2-}$ ions in the wurtzite structure surrounded by the $\mathrm{Zn}$ atoms with the full supplement of nearest-neighbour $\mathrm{O}^{2-}$ ions. ${ }^{62}$ The peak at $531.5 \pm 0.3 \mathrm{eV}$ is associated with $\mathrm{O}^{2-}$ ions that are in the oxygen-deficient regions within the $\mathrm{ZnO}$ matrix. ${ }^{62}$ The peak at $532.3 \pm 0.3 \mathrm{eV}$ is attributed to chemisorbed or dissociated $\mathrm{O}_{2}$ or $-\mathrm{OH}$ species on the surface of the $\mathrm{ZnO}$ thin film, such as $-\mathrm{CO}_{3}$, adsorbed $\mathrm{H}_{2} \mathrm{O}$ or adsorbed $\mathrm{O}_{2} \cdot{ }^{62}$ It is very interesting to note that in contrast to $\mathrm{A} 2$ and $\mathrm{B} 2$, for both $\mathrm{A} 3$ and $\mathrm{B} 3$ films, the $\mathrm{O} 1 \mathrm{~s}$ peak could be fitted with two peaks showing more $\mathrm{O}$ content (more relative peak area) possibly due to the more adsorbed $\mathrm{O}_{2}$ molecules at the less strained $O$ vacancy sites. ${ }^{63}$ Therefore the XPS results clearly indicate and support tuning the defects by simply controlling the cooling step. 

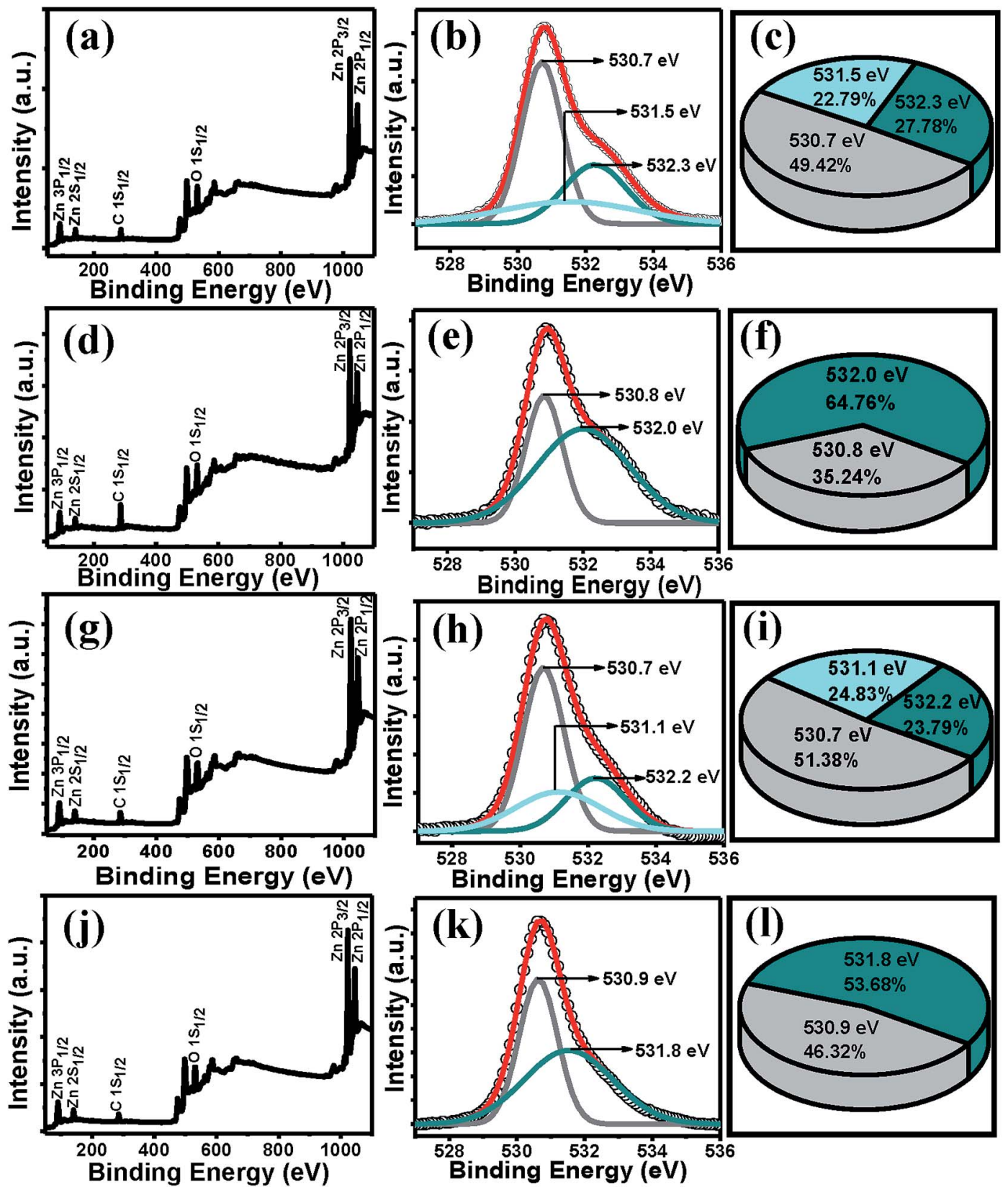

Fig. 6 XPS full scan of (a) A2, (d) A3, (g) B2, (j) B3 films. Deconvoluted O 1s $s_{1 / 2}$ peak of (b) A2 (e) A3 (h) B2 (k) B3. Pie-chart of the relative peak areas (c) A2, (f) A3, (i) B2, (l) B3 films.

\section{Conclusion}

In conclusion, we have shown a simple, straight forward and quick way to control the defects to tune the optical emission and ultraviolet photosensing properties of sol-gel $\mathrm{ZnO}$ films. Improving the PL properties as an enhanced UV/VIS emission intensity ratio was demonstrated in the rapidly cooled films irrespective of the preheat treatment procedure. Not only photoluminescence, but highly enhanced UV photoresponse due to higher $\mathrm{O}_{2}$ molecule adsorption on $\mathrm{ZnO}$ surface was observed in the rapidly cooled films. Our results give an insight into the importance of a simple process step for controlling the photoluminescence and photoconductivity properties with an eye on practical applications.

\section{Acknowledgements}

One of the authors, S. Ghosh would like to thank CSIR, India for providing the fellowship vide Ref no: 22/12/2013(ii)EU-V.

\section{References}

1 S. H. Hsu, Y. Y. Lin, S. Huang, K. W. Lem, D. H. Nguyen and D. S. Lee, Nanotechnology, 2013, 24, 475102.

2 A. A. Mosquera, D. Horwat, A. Rashkovskiy, A. Kovalev, P. Miska, D. Wainstein, J. M. Albella and J. L. Endrino, Sci. Rep., 2013, 3, 1714.

3 S. Dhara and P. K. Giri, Nanoscale Res. Lett., 2011, 6, 504. 
4 S. F. Varol, G. Babur, G. Cankaya and U. Kolemen, RSC Adv., 2014, 4, 56645-56653.

5 A. Mallick, A. Kole, T. Ghosh, P. Chaudhuri and D. Basak, Sol. Energy, 2014, 108, 80-87.

6 A. I. Inamdar, S. H. Mujawar, S. R. Barman, P. N. Bhosale and P. S. Patil, Semicond. Sci. Technol., 2008, 23, 085013.

7 B. Pare, P. Singh and S. B. Jonnalgadda, J. Sci. Ind. Res., 2009, 68, 724-729.

8 C. Soci, A. Zhang, B. Xiang, S. A. Dayeh, D. P. R. Aplin, J. Park, X. Y. Bao, Y. H. Lo and D. Wang, Nano Lett., 2007, 7, 10031009.

9 S. Kiruthika, S. Singh and G. U. Kulkarni, RSC Adv., 2016, 6, 44668-44672.

10 R. Paul, R. N. Gayen, S. Biswas, S. V. Bhat and R. Bhunia, RSC Adv., 2016, 6, 61661-61672.

11 J. G. Lu, Z. Z. Ye, Y. Z. Zhang, Q. L. Liang, S. Fujita and Z. L. Wang, Appl. Phys. Lett., 2006, 89, 023122.

12 S. A. Ansari, M. M. Khan, S. Kalathil, A. Nisar, J. Lee and M. H. Cho, Nanoscale, 2013, 5, 9238-9246.

13 N. Gogurla, A. K. Sinha, S. Santra, S. Manna and S. K. Ray, Sci. Rep., 2014, 4, 6483.

14 R. Dingle, Phys. Rev. Lett., 1969, 23, 579-581.

15 Y. I. Alivov, M. V. Chukichev and V. A. Nikitenko, Semiconductors, 2004, 38, 31-35.

16 F. H. Leiter, H. R. Alves, A. Hofstaetter, D. M. Hofmann and B. K. Meyer, Phys. Status Solidi B, 2001, 226, R4-R5.

17 F. Leiter, H. Alves, D. Pfisterer, N. G. Romanov, D. M. Hofmann and B. K. Meyer, Phys. B, 2003, 340, 201-204.

18 S. Wilken, J. Parisi and H. Borchert, J. Phys. Chem. C, 2014, 118, 19672-19682.

19 Z. C. Pan, X. L. Tian, S. K. Wu, C. M. Xiao, Z. L. Li, J. F. Deng, G. H. Hu and Z. G. Wei, Superlattices Microstruct., 2013, 54, 107-117.

20 Z. C. Pan, P. W. Zhang, X. L. Tian, G. Cheng, Y. H. Xie, H. C. Zhang, X. F. Zeng, C. M. Xiao, G. H. Hu and Z. G. Wei, J. Alloys Compd., 2013, 576, 31-37.

21 L. Chen, T. T. Tran, C. A. Huang, J. Z. Li, L. J. Yuan and Q. Y. Cai, Appl. Surf. Sci., 2013, 273, 82-88.

22 S. Sharma, S. Vyas, C. Periasamy and P. Chakrabarti, Superlattices Microstruct., 2014, 75, 378-389.

23 S. Dhara and P. K. Giri, Thin Solid Films, 2012, 520, 50005006.

24 N. Srinatha, Y. S. No, V. B. Kamble, S. Chakravarty, N. Suriyamurthy, B. Angadi, A. M. Umarji and W. K. Choi, RSC Adv., 2016, 6, 9779-9788.

25 Q. J. Feng, S. Liu, Y. Liu, H. F. Zhao, J. Y. Lu, K. Tang, R. Li, K. Xu and H. Y. Guo, Mater. Sci. Semicond. Process., 2015, 29, 188-192.

26 S. D. Shinde, S. K. Date, A. V. Deshmukh, A. Das, P. Misra, L. M. Kukreja and K. P. Adhi, RSC Adv., 2015, 5, 2417824187.

27 K. Sivalingam, P. Shankar, G. K. Mani and J. B. B. Rayappan, Mater. Lett., 2014, 134, 47-50.

28 J. Zhang, H. Yang, Q. L. Zhang, S. R. Dong and J. K. Luo, Appl. Phys. Lett., 2013, 102, 012113.
29 M. A. Boukadhaba, A. Fouzri, V. Sallet, S. S. Hassani, G. Amiri, A. Lusson and M. Oumezzine, Superlattices Microstruct., 2015, 85, 820-834.

30 M. Asghar, K. Mahmood, M. A. Hasan, I. T. Ferguson, R. Tsu and M. Willander, Chin. Phys. B, 2014, 23, 097101.

31 V. Kumar, S. Som, A. Yousif, N. Singh, O. M. Ntwaeaborwa, A. Kapoor and H. C. Swart, J. Colloid Interface Sci., 2014, 428, 8-15.

32 M. Dutta, S. Mridha and D. Basak, Appl. Surf. Sci., 2008, 254, 2743-2747.

33 S. K. Shaikh, S. I. Inamdar, V. V. Ganbavle and K. Y. Rajpure, J. Alloys Compd., 2016, 664, 242-249.

34 Advanced X-ray Techniques in Research and Industry (Stand Alone), ed. A. K. Singh, IOS Press, Amsterdam, 2005.

35 W. Pompe, X. Gong, Z. Suo and J. S. Speck, J. Appl. Phys., 1993, 74, 6012-6019.

36 H. C. Ong, A. X. E. Zhu and G. T. Du, Appl. Phys. Lett., 2002, 80, 941-943.

37 S. Weissmann, B. Post, M. E. Mrose, H. F. McMurdie, M. C. Morris and W. F. McClune, Selected Power Diffraction Data for Metals and Alloys, JCPDS, USA, 1978, vol. I, p. 108.

38 Photonics and Electronics with Germanium, ed. K. Wada and L. C. Kimerling, John Wiley \& Sons, 2015.

39 M. S. Kim, K. G. Yim, D. Y. Lee, J. S. Kim, J. S. Son and J. Y. Leem, Appl. Surf. Sci., 2011, 257, 9019-9023.

40 E. A. Davis and N. F. Mott, Philos. Mag., 1970, 22, 903-922.

41 R. Ghosh, D. Basak and S. Fujihara, J. Appl. Phys., 2004, 96, 2689-2692.

42 S. Mondal and D. Basak, J. Lumin., 2016, 179, 480-486.

43 D. Sett, S. Sarkar and D. Basak, RSC Adv., 2014, 4, 5855358558.

44 B. Guo, Z. R. Qiu and K. S. Wong, Appl. Phys. Lett., 2003, 82, 2290-2292.

45 F. K. Shan, G. X. Liu, W. J. Lee, G. H. Lee, I. S. Kim and B. C. Shin, Appl. Phys. Lett., 2005, 86, 221910.

46 M. Liu, A. H. Kitai and P. Mascher, J. Lumin., 1992, 54, 35-42. 47 D. C. Reynolds, D. C. Look, B. Jogai, J. E. Hoelscher, R. E. Sherriff, M. T. Harris and M. J. Callahan, J. Appl. Phys., 2000, 88, 2152-2153.

48 U. Ozgur, Y. I. Alivov, C. Liu, A. Teke, M. A. Reshchikov, S. Dogan, V. Avrutin, S. J. Cho and H. Morkoc, J. Appl. Phys., 2005, 98, 041301.

49 J. W. Fang, H. Q. Fan, Y. Ma, Z. Wang and Q. Chang, Appl. Surf. Sci., 2015, 332, 47-54.

50 A. Bera and D. Basak, Appl. Phys. Lett., 2009, 94, 163119.

51 M. A. Reshchikov, J. Q. Xie, B. Hertog and A. Osinsky, J. Appl. Phys., 2008, 103, 103514.

52 R. Vidya, P. Ravindran, H. Fjellvag, B. G. Svensson, E. Monakhov, M. Ganchenkova and R. M. Nieminen, Phys. Rev. B: Condens. Matter Mater. Phys., 2011, 83, 045206.

53 R. Ghosh, G. K. Paul and D. Basak, Mater. Res. Bull., 2005, 40, 1905-1914.

54 T. Minami, H. Nanto and S. Takata, Thin Solid Films, 1983, 109, 379-384.

55 V. Avrutin, D. J. Silversmith and H. Morkoc, Proc. IEEE, 2010, 98, 1269-1280. 
56 A. Janotti and C. G. Van de Walle, Phys. Rev. B: Condens. Matter Mater. Phys., 2007, 76, 165202.

57 B. Mallampati, S. V. Nair, H. E. Ruda and U. Philipose, J. Nanopart. Res., 2015, 17, 176.

58 M. Gsell, P. Jakob and D. Menzel, Science, 1998, 280, 717720.

59 D. Basak, G. Amin, B. Mallik, G. K. Paul and S. K. Sen, J. Cryst. Growth, 2003, 256, 73-77.
60 A. E. Jimenez-Gonzalez, J. A. S. Urueta and R. Suarez-Parra, J. Cryst. Growth, 1998, 192, 430-438.

61 S. Mridha and D. Basak, Chem. Phys. Lett., 2006, 427, 62-66. 62 B. Pal, D. Sarkar and P. K. Giri, Appl. Surf. Sci., 2015, 356, 804-811.

63 A. Schlapka, M. Lischka, A. Gross, U. Kasberger and P. Jakob, Phys. Rev. Lett., 2003, 91, 016101.

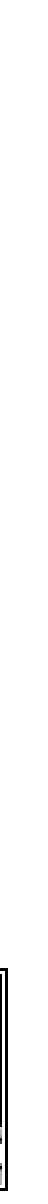

